\title{
Instituições financeiras públicas de fomento: exagero de conservadorismo da política de investimentos?*
}

\author{
Paulo Rogério F. Matos** \\ José Valente de Lima Filho***
}

Sumário: 1. Introdução; 2. A tesouraria do Banco do Nordeste do Brasil; 3. Modelagem teórica; 4. Exercício empírico; 5. Resultados; 6. Conclusão.

Summary: 1. Introduction; 2. Northeast Bank of Brazil's treasury; 3. Theoretical modelling; 4. Empirical exercise; 3. Results; 6. Conclusion.

Palavras-chave: capital asset pricing model; tesouraria de instituições financeiras públicas; mudanças institucionais.

KEY WORDs: capital asset pricing model; public financial institutions' treasuries; institutional changes.

Este artigo analisa a questão do conservadorismo no que concerne à gestão de recursos por tesourarias de instituições financeiras públicas, que incorrem em um trade-off por não ter essa gestão como prioridade, mas sim as atividades associadas ao desenvolvimento. Fazendo-se uso do capital asset pricing model (CAPM), as evidências para o Banco do Nordeste do Brasil, o maior banco de desenvolvimento regional da América Latina, sugerem que sejam viáveis as mudanças institucional e na legislação que restringe a política de investimentos dessas organizações.

\footnotetext{
* Artigo recebido em set. 2008 e aceito em out. 2009.

** Doutor em economia pela Escola de Pós-Graduação em Economia da Fundação Getulio Vargas (EPGE/FGV). Professor adjunto da Pós-Graduação em Economia da Universidade Federal do Ceará (Caen). Pesquisador do CNPq e professor convidado da FGV Management. Endereço: Avenida da Universidade, 2700, $2^{\circ}$ andar — Benfica - CEP 60020181, Fortaleza, CE, Brasil. E-mail: paulo. matos@fgv.bre paulomatos@caen.ufc.br.

**** Mestre em economia e graduado em jornalismo pela Universidade Federal do Ceará. Há 13 anos atua no mercado financeiro, atualmente como gerente de negócios da Área de Operações Financeiras do Banco do Nordeste do Brasil. E-mail: valente@bnb.gov.br.
} 


\begin{abstract}
Public development financial institutions: excessively conservative investment policies?

This article analyzes the conservative behavior of public financial institutions' treasuries, which incur a trade-off for prioritizing their development-related activities instead of their funds management. Using the capital asset pricing model (CAPM), evidence from the Northeast Bank of Brazil, the largest regional development bank in Latin America, suggests that changes in the institutions, as well as in the legislation that restricts their investment policy, are feasible.
\end{abstract}

\title{
1. Introdução
}

A tesouraria exerce papel fundamental no gerenciamento da liquidez de uma instituição financeira. No entanto, sua contribuição para com a geração de receitas da instituição depende de fatores como o montante de recursos disponíveis e principalmente do perfil desta, se pública ou privada.

Em uma instituição pública de desenvolvimento regional, como o Banco do Nordeste do Brasil (BNB) ou o Banco da Amazônia (Basa), com função precípua de fornecer crédito de médio e longo prazos para o estabelecimento de empreendimentos econômicos produtivos na região em questão, a tesouraria possui certamente menos "destaque" do que a área operacional, mesmo que sua importância possa ser expressa em números. Em 2006, por exemplo, a tesouraria do BNB contribuiu com mais de um quarto das receitas brutas da empresa. Esse desempenho, que segue orientação histórica padrão desde o início das operações da instituição, em 1954, foi atingido por meio de uma política conservadora de investimentos.

Como lidar diante desse trade-off comum a instituições de fomento, cuja prioridade não é o lado dito comercial, mesmo sendo este relevante para a "saúde financeira" da instituição, mas sim primar pela execução de uma política de desenvolvimento ágil e seletiva, capaz de contribuir como agente indutor do desenvolvimento sustentável da região Nordeste? Até que ponto valeria envidar esforços e alocar recursos visando aprimorar este que não pode ser o setor prioritário da instituição?

Este artigo analisa a performance da carteira de investimentos do Banco do Nordeste do Brasil, o maior banco de desenvolvimento regional da América Latina, que diferencia-se das demais instituições financeiras pela missão de atuar, na capacidade de instituição financeira pública, como agente catalisador do desenvolvimento sustentável do Nordeste, integrando-o na dinâmica da economia nacional. 
Pretende-se inicialmente mensurar tal desempenho a partir da medida de Jensen, sugerida em 1968, como uma aplicação empírica do tradicional capital asset pricing model (CAPM), o modelo mais famoso e usado para qualificar as decisões de gerentes de recursos financeiros no que se refere à sua adequada alocação. No artigo é possível identificar potenciais melhorias de desempenho e propiciar subsídios para uma análise mais profunda e abalizada sobre a relação custo-benefício de se expandir um corpo técnico vis-à-vis as novas necessidades. Em um segundo momento, este pode ser visto como um artigo pioneiro em uma linha ainda embrionária no país, em que se pretende subsidiar possíveis mudanças na lei que regula as limitações de risco a serem incorridos pela gestão de tesouraria em instituições financeiras públicas, ou mesmo em órgãos governamentais.

Em suma, é possível evidenciar que se atendo aos limites impostos à política de investimentos do BNB, seria possível obter um ganho ajustado pelo risco de $0,2 \%$, já para o caso de carteiras um pouco mais arrojadas e além dos atuais limites tal ganho seria de $0,23 \%$ ao ano. De acordo com tais resultados não triviais, não seria possível ainda ter uma completa e definitiva análise de custo-benefício quanto à mudança da política de gestão de recursos de tesouraria do $\mathrm{BNB}$, ou ainda para a mudança de legislação, mas sugere que ambas sejam viáveis, pois o ganho ajustado pelo risco estaria na ordem de grandeza de $\mathrm{R} \$ 15$ milhões ao ano, possivelmente capaz de acomodar associados à mudança institucional.

Segundo a estrutura deste artigo, na próxima seção haverá uma breve abordagem sobre a política de tesouraria do BNB, seguida de uma descrição mais detalhada da modelagem teórica a ser utilizada. Na seção 4, apresentamse os aspectos técnicos concernentes ao teste empírico do modelo com a discussão dos respectivos resultados. Na seção 6, estão as considerações finais.

\section{A tesouraria do Banco do Nordeste do Brasil}

Instituição criada pela Lei no 1.649, de 19 de julho de 1952, para fomentar o desenvolvimento da região Nordeste do país, o Banco do Nordeste do Brasil possui uma política de gestão de recursos de tesouraria que se caracteriza pelo conservadorismo. Tal postura decorre do entendimento - expresso nas políticas internas da empresa - de que a atividade de tesouraria é apenas complementar à principal atribuição da instituição, que atua predominantemente no crédito de longo prazo, baseado em financiamentos produtivos. 
Embora como banco múltiplo autorizado a operar as carteiras de desenvolvimento, comercial e de investimento, o BNB possa efetuar operações com os mais diversos ativos do mercado financeiro - à exceção de participações acionárias em outras empresas —, as políticas da instituição orientam-no a fazê-lo sempre sob uma ótica de grande aversão ao risco.

Dessa forma, operações com derivativos são efetuadas apenas para efeito de proteção da carteira. O portfólio da tesouraria do BNB concentra-se em títulos públicos principalmente, com a carteira de renda fixa correspondendo, historicamente, a mais da metade do total de disponibilidades financeiras da instituição. Esses mesmos títulos públicos são negociados diariamente com outras instituições, para suprir as necessidades de caixa, por meio de operações ditas "compromissadas", pois são efetuadas sempre com o "compromisso" das duas instituições envolvidas de "desfazer" a operação inicial por meio da assunção de uma operação inversa à original. Ou seja, se é efetuada uma operação de captação de recursos financeiros e um montante de títulos é vendido a outro banco, imediatamente é negociada a operação de recompra. Similarmente, uma operação de aplicação, ou compra de títulos, é negociada em paralelo à operação de revenda desses mesmos ativos, normalmente com o prazo de apenas um dia, numa rotina comum às mesas de operações do mercado interbancário brasileiro.

Somadas as operações compromissadas e a carteira de renda fixa, temos quase a totalidade do portfólio de tesouraria do banco. De forma historicamente residual, o BNB também aplica em certificados de depósitos interfinanceiros (CDI) e, por decisão do governo federal, possui pequena monta de recursos alocados - e imobilizados - em renda variável, fruto de um aumento de capital realizado sob a forma de participação acionária em dezembro de 1996. Entretanto, da mesma forma que as demais entidades da administração governamental federal, o BNB ficou proibido pelo Decreto no 1.068 , de 2 de março de 1994, de assumir participações societárias em sociedades de capital aberto, a não ser em casos expressamente autorizados pelo governo, como o aporte supracitado.

Em resumo, o BNB diferencia-se das demais instituições focadas em operações comerciais e de investimento por evitar as apostas tradicionalmente efetuadas por grandes bancos em mercados futuros, de opções e outras posições em renda variável. Também não possui em carteira outros ativos de renda fixa, como debêntures, fundos de investimento em direitos creditórios (FIDCs) e certificados de recebíveis imobiliários (CRIs). O controle estreito dos riscos operacional, de mercado, de liquidez e de crédito faz parte de suas diretrizes estratégicas, com limites estabelecidos para operacionalização de ativos de 
uma mesma instituição privada com base nos patrimônios de referência respectivos. Essa metodologia de controle segue um padrão de regulamentação estabelecido pela autoridade monetária, cujo marco legal - a Resolução $\mathrm{n}^{0}$ 2.099, de 17 de agosto de 1994, do Banco Central e, mais recentemente, sua atualização, a Resolução ㄲo 3.490, de 29 de agosto de 2007 — também toma como base os patrimônios de referência das instituições do mercado financeiro para estabelecer limites de operações ativas.

Na ausência de uma legislação específica que proíba a execução de operações financeiramente alavancadas ou em outros ativos comumente negociados no mercado financeiro, essa particularidade do BNB em relação às outras instituições do mercado é fruto de uma decisão gerencial. Dada a relativa liberdade que o banco possui na seleção dos ativos que compõem sua carteira de tesouraria - relativa porque as resoluções supracitadas obrigam a manutenção de um patrimônio de referência compatível com os riscos incorridos por cada instituição financeira - , faz-se necessária uma avaliação do desempenho da carteira de tesouraria do banco, a fim de nortear eventuais mudanças ou a continuidade das políticas internas da instituição.

\section{Modelagem teórica}

\section{Breve histórico}

Vargas e Leal (Cassettari, 2006) dizem que "uma das mais importantes questões das teorias financeiras diz respeito à administração eficiente de carteiras". De um modo geral, os envolvidos com a teoria das carteiras sempre se preocupam com a alocação eficiente do capital. Assim, é de muito tempo que o tema é estudado e ainda permanece muito atual.

Nos primeiros estudos a intuição sobre o assunto estava correta, o que se buscava era a identificação de seus dois conceitos básicos: risco e retorno. No entanto, somente com Markowitz (1952), foram lançadas as bases da que ficou conhecida como The modern portfólio theory. O relevante dessa teoria foi formalizar a relação risco e retorno. Até então, o desempenho de uma carteira era medido em termos de quanto dinheiro o investidor tinha ganhado ou perdido, sem referência ao risco incorrido. O trabalho de Markowitz proporcionou a noção exata do efeito da diversificação de ativos para reduzir a variância de uma carteira. $O$ estudo deixou claro que uma diversificação poderia reduzir ou, até mesmo, teoricamente, eliminar os riscos. Simultaneamente, sua teoria trouxe à tona uma nova variável: a correlação entre os ativos que, a partir de 
então, passou a ter extrema importância na seleção de ativos para composição de portfólios.

De forma sucinta, a regra básica seria de que ganho esperado e risco seriam, na verdade, os únicos a serem levados em consideração na seleção de uma carteira, e que o retorno seria o fator desejável pelo investidor, e a variância indesejável. Assim, o investidor racional desejaria maximizar o fator desejável e minimizar o indesejável. A escolha da função risco-retorno tem por finalidade tratar quantitativamente os ativos financeiros. Essa simplificação da realidade permite ao investidor tratar de forma fácil e intuitiva suas decisões sobre investimentos, possibilitando, por exemplo, o uso de uma curva de indiferença que facilita a visualização do ativo mais apropriado a um determinado investidor, dado o grau de predisposição ao risco dele. Essa teoria de carteiras revolucionou a profissão de gestão de investimentos elevando o risco à igual importância do retorno esperado. Seu trabalho proveu as bases sobre as quais se erigiram quase todos os estudos de finanças que se seguiram.

\section{O capital asset pricing model}

Decorrente diretamente da teoria de seleção de carteiras de Markowitz (1952), Sharpe (1964), Lintner (1965) e Mossin (1966) desenvolvem o CAPM (Capital asset pricing model), que mostra que as taxas de retorno em equilíbrio dos ativos de risco são uma função de suas covariâncias com a carteira de mercado. Bodie e Merton (2002) enfatizam que "a ideia fundamental subjacente ao CAPM é que, em equilíbrio, o mercado recompensa as pessoas por assumirem riscos". Bonomo destaca que o CAPM "vem a ser o primeiro e mais famoso e utilizado modelo de apreçamento de ativos". Assim, o primeiro modelo de apreçamento de ativos deste artigo é o CAPM. Por ser um dos modelos mais utilizados, seja em mercados de capitais ou em finanças corporativas, na definição do custo de capital, o CAPM também é um dos mais pesquisados na área de finanças. Desde sua formulação, na metade da década de 1960, até os dias de hoje, diversos pesquisadores têm procurado testá-lo empiricamente, defendendo-o ou promulgando sua não validade. Várias extensões foram sugeridas na tentativa de melhorá-lo, elucidando novos fatores de risco possíveis e criando-se novos modelos capazes de prever retornos futuros com maior exatidão. Assim, procura-se acompanhar os trabalhos desenvolvidos na área, tanto no mercado americano como no mercado brasileiro, investigando se este mercado se comporta conforme os modelos formulados para mercados desenvolvidos. 
Contudo, observa-se que, apesar da extensa bibliografia sobre o assunto, os resultados das pesquisas ainda são controversos. As evidências empíricas apontam para outros fatores de risco além do beta, que representa o modelo CAPM, de mercado, mas os resultados não são unânimes. As hipóteses para retornos anômalos ao modelo passam não só pelo relaxamento das premissas racionais da formulação original do CAPM, como também pela possibilidade de comportamento irracional por parte dos agentes. A seguir, as premissas básicas do modelo:

v as informações do mercado são livres, conhecidas e acessíveis a todos, sem custos;

V os investidores concordam em suas previsões sobre as taxas de retorno esperadas, os desvios padrão e a correlação dos ativos de risco; assim, mantêm, de forma ótima, ativos de risco nas mesmas proporções relativas;

v os investidores são racionais e se comportam de forma otimizada. No equilíbrio, os preços dos títulos ajustam-se, de modo que, quando os investidores estão mantendo suas carteiras ótimas, a demanda agregada para cada título é equivalente à sua oferta;

v nenhum investidor é forte o suficiente para provocar oscilações nas taxas de mercado;

v não há restrições à entrada de novos investidores no mercado, e estes podem emprestar ou tomar emprestado;

v não existem custos ou impostos sobre as transações.

Como principal resultado deste arcabouço, o retorno excedente esperado de qualquer ativo seria uma função linear do beta (coeficiente de sensibilidade do ativo em relação à carteira de mercado) e do retorno excedente esperado de mercado, conforme a seguinte fórmula:

onde

$$
E\left(R_{i}\right)-R_{f}=\hat{a}_{i} \cdot\left[E\left(R_{m}\right)-R_{f}\right]
$$

$R_{i}$ - retorno real do ativo $i$;

$R_{f}$ - retorno real de uma proxy para o ativo livre de risco;

$R_{m}$ - retorno real de uma proxy para a carteira de mercado;

$E($.$) - operador esperança;$

$\beta_{i}$ - coeficiente de sensibilidade do ativo $i$ em relação à carteira de mercado.

A relação expressa pela equação (1) se chama linha de mercado de títulos (LMT). A diferença entre a taxa de retorno média de um título ou de uma 
carteira de ações e a relação de sua LMT é chamada de alfa. Se um gerente de carteira puder produzir consistentemente um alfa positivo, seu desempenho é tido como superior.

Desde o seu surgimento, o CAPM tornou-se a base da maior parte dos trabalhos que procuram analisar o desempenho de uma carteira de investimentos. Estudos que procuram uma alternativa ao modelo surgiram na esteira da tentativa de impor mais realismo ao CAPM, como considerar custos de tomar empréstimos e restrições à entrada de novos investidores. Uma dessas propostas foi apresentada por Merton (1973), que criou o modelo intertemporal de apreçamento de ativos de capital (ICAPM) multifator, no qual os prêmios de risco do equilíbrio sobre os títulos neste modelo dinâmico vêm de diversas dimensões de riscos, refletidas não apenas por suas sensibilidades de retorno ou beta na carteira do mercado, mas também por sua sensibilidade a outros riscos sistemáticos, como mudanças em taxas de juros e retornos esperados sobre ativos e mudanças nos preços dos bens de consumo. Mas, embora a estrutura específica de riscos do ativo nessas alternativas difira do CAPM, os discernimentos básicos do modelo - em que os prêmios de risco são relacionados a fatores de risco sistemáticos amplos que importam para um grande segmento da população — ainda se mantêm.

\section{A medida de desempenho de Jensen}

A medida de desempenho de Jensen (1968) foi apresentada em 1968 e baseou-se no modelo CAPM aplicado a uma carteira de investimento em função de seus prêmios de risco realizados. Segundo Jensen, caso o gestor possua uma habilidade superior na gestão da carteira, o ativo tenderá a apresentar sistematicamente retornos superiores aos obtidos na equação (1). A solução proposta por Jensen possui a equação (1) como caso particular em que o intercepto $\left(a_{i}\right)$ a ser estimado seja estatisticamente nulo na seguinte regressão (2):

$$
R_{i}-R_{f}=a_{i}+\hat{a}_{i} \cdot\left[R_{m}-R_{f}\right]+u_{i}
$$

Neste arcabouço, estimações positivas significativas para $\alpha$ sugeririam um desempenho da carteira superior à expectativa do mercado relativamente a seu nível de risco sistemático e evidenciam habilidade do gestor em selecionar ativos para a carteira. Observando-se painéis extensos de ações e índices é possível evidenciar que uma distribuição dos $\alpha$ 's em torno de zero, mas não necessariamente com insignificância estatística.

Note-se a diferença prática em relação ao CAPM, cuja equação mais conhecida pressupõe o uso de expectativas dos investidores, por meio da inserção de re- 
tornos esperados. Acontece que retornos esperados são difíceis de ser mensurados de forma prática, restando-nos a observação de retornos realizados numa série histórica. Além disso, substituímos a carteira de mercado por um índice de mercado observável. O modelo de índice único proposto por Jensen pode ser entendido como uma versão do modelo CAPM com a adição de um $\alpha$ ( $\alpha$-Jensen).

A escolha de um modelo derivado do CAPM encontra respaldo nos inúmeros estudos relacionados ao desempenho de carteiras de investimento. Leal e Vilella (2006) utilizaram o $\alpha$-Jensen na análise de desempenho de fundos balanceados. Vargas (2006a) também o utiliza, dessa vez para verificar a eficiência de fundos de ações com gestão ativa no Brasil, mencionando-o também em outro trabalho, em que derivam indicadores utilizados em avaliação de performance de investimentos Vargas (2006b). De maneira mais abrangente, o volume de trabalhos utilizando modelos derivados do CAPM para a avaliação de desempenho de investimentos é vasto. Sousa e Luporini (1997), por exemplo, fazem um apanhado de indicadores com base no modelo - índice de Sharpe, de Treynor e de Jensen - para a análise empírica de fundos mútuos de ações brasileiros.

Uma extensão do estudo poderia utilizar o modelo proposto por Owen e Rabinovitch (1998), que sugerem um método alternativo aos derivados do CAPM, comparando o desempenho de duas carteiras quaisquer com base no critério de dominância de média-variância. Dada uma série de $n$ portfólios, cada um deles é comparado com os $N-1$ restantes, produzindo uma matriz $N$ x $N$ contendo o resultado de todas as comparações. Posteriormente, o modelo emprega uma função de ranking, que estabelece uma completa hierarquia com os resultados evidenciados na matriz. A proposta difere dos demais modelos com base no CAPM em alguns pontos: estes estabelecem um escore independente a cada carteira, enquanto aquela faz comparações "dois a dois" e estabelece a hierarquia com base nessas comparações; os modelos derivados do CAPM usam uma medida com base exclusivamente nos retornos, isto é, a classificação é baseada no retorno médio ajustado ao risco, enquanto Owen e Rabinovitch propõem o critério relacionado à dominância de média-variância; na medida em que são utilizadas comparações "dois a dois", o modelo independe de um benchmark; finalmente, o modelo também independe da utilização de uma taxa livre de risco.

\section{Exercício empírico}

Neste artigo, utilizaremos o modelo de Jensen, derivado do CAPM, para avaliar o desempenho da tesouraria do Banco do Nordeste no período que vai de janeiro de 2003 a dezembro de 2007. Serão utilizados dados mensais de retor- 
nos da carteira da empresa, englobando um total de cinco anos, deflacionados pelo IPCA do período e retornos mensais de ativos outros, não utilizados pela empresa em seu portfólio de tesouraria durante estes cinco anos, a título de sugestão de carteiras alternativas. Tais ativos englobam debêntures, fundos de investimento em direitos creditórios (FIDCs) e contratos futuros de DI. Esses novos portfólios serão avaliados comparativamente à carteira efetivamente praticada pelo banco, de forma a verificar a habilidade do gestor na seleção dos ativos que compõem a carteira de tesouraria do BNB.

O exercício empírico será feito a partir da regressão (2)

$$
R_{i}-R_{f}=a_{i}+\hat{a}_{i} \cdot\left[R_{m}-R_{f}\right]+u_{i}
$$

fazendo-se uso do método de estimação dos mínimos quadrados ordinários, levando-se em consideração a construção de uma matriz de variância e covariância robusta à heterocedasticidade e correlação serial proposta por Newey e West (1987). Sabe-se que a utilização do estimador não irá mudar os valores estimados dos parâmetros, mas irá proporcionar o erro-padrão e o consequente p-valor corretos.

Após testarmos o modelo, os portfólios que apresentarem estimativas de $\alpha$ positivas e estatisticamente significantes - entre eles o portfólio atual do banco - denotarão um desempenho superior à expectativa do mercado relativamente a seu nível de risco sistemático. Aquele que apresentar alfa positivo, estatisticamente significante e superior aos demais, poderá ser considerado a melhor alternativa de carteira frente às demais rodadas com o modelo. Para a análise do desempenho de carteiras alternativas ao portfólio tradicionalmente aplicado pelo banco, será utilizada, como critério de alocação de recursos, a política de tesouraria da empresa, que estabelece limites para compra de papéis privados. Esses limites têm como base o patrimônio de referência do banco, e, portanto, variam mês a mês. Para efeitos deste artigo, foi considerado o limite médio observado durante o período abrangido pela amostra de dados, isto é, uma concentração máxima, por ativo, de 2,8\% do total da carteira do banco, além de 5,6\% de exposição máxima a papéis privados. Entretanto, também foram feitos testes superando tais limites, visando à verificação do desempenho de portfólios alternativos que eventualmente venham a ensejar alterações na política de tesouraria da instituição.

\section{Resultados}

\section{Dados}

Os dados utilizados em nosso estudo compreendem séries históricas da taxa de poupança, que será utilizada como taxa livre de risco. A poupança - cuja 
remuneração é estabelecida pela TR e um percentual fixo de $0,5 \%$ capitalizados mensalmente - possui um desempenho médio inferior à remuneração proporcionada pela Selic.

A remuneração superior proporcionada por um ativo é entendida, em finanças, como um prêmio pelo maior risco incorrido - a clássica relação de trade-off existente entre risco e retorno. Por esse raciocínio, poderíamos considerar a poupança menos arriscada que os títulos públicos do governo. Mais relevante ainda que esse ponto é o fato de que a volatilidade da poupança pode ser facilmente comparada a taxas de juros em economias desenvolvidas, assumindo um patamar de quase $3 \%$ ao ano, enquanto a volatilidade da Treasury Bill do governo americano é da ordem de $3,1 \%$ ao ano e a Selic de quase 10\% ao ano, considerando-se os dados trimestrais de 1995 até 2007.

O índice da Bolsa de Valores de São Paulo (Ibovespa) será usado como nosso benchmark de carteira de mercado, enquanto as carteiras alternativas, cujo retorno excedente consiste na variável dependente a ser apreçada pelo CAPM, serão compostas a partir de pequenas variações da atual carteira de tesouraria do BNB, acrescidas do retorno mensal oferecido por debêntures das empresas Nova Marlim, Petrobras e Itaubank Leasing, do retorno mensal oferecido pelos FIDCs Auto Pan, Ideal e Máster, e da variação mensal obtida com a compra de contratos futuros de DI.

A seleção das debêntures utilizadas no estudo obedeceu a um critério de atividade e classificação de risco: os papéis foram selecionados entre os emitidos antes de janeiro de 2003 e com vencimento posterior a dezembro de 2007, que ainda estivessem com o registro ativo no Sistema Nacional de Debêntures, cujas empresas emissoras tivessem classificação de risco estipulada por, pelo menos, uma agência internacional (Fitch Ratings, Austin Ratings, Moody's Investors Service ou Standard and Poor's) e a nota de classificação fosse, no mínimo A, que atesta a qualidade média/alta de atender a compromissos financeiros. Portanto, com risco de crédito relativamente baixo, conforme requisita a política de tesouraria adotada pelo BNB. A seleção dos FIDC's obedeceu aos mesmos critérios de conservadorismo no que se refere a risco de crédito, e foram escolhidos aqueles que obtiveram o melhor desempenho associado à significância estatística. Devido à relativa incipiência dessa modalidade de ativo financeiro (os FIDCs foram regulamentados pela Instrução CVM no 356, de dezembro de 2001), as séries históricas dos FIDCs Auto Pan e Máster têm início em fevereiro de 2004. A série histórica do fundo Ideal iniciase em abril de 2004. Assim, as carteiras que utilizam esses FIDCs têm o perfil de portfólios dinâmicos, em que a composição somente passa a considerá-los a partir do início de sua rentabilidade - a proporção anterior é ocupada pelo retorno proporcionado pela renda fixa. 
A utilização de contratos futuros de DI foi inserida na sugestão de carteiras mais arrojadas que o BNB possa vir a adotar. Embora esteja prevista pela política da empresa a utilização de derivativos apenas como proteção (hedge), não há um impeditivo legal para a inserção deles na carteira de tesouraria, sendo possível sua utilização, conforme o entendimento gerencial. A escolha pelos contratos futuros de DI entre as várias opções de derivativos existentes leva em consideração o contexto histórico vivenciado no início de 2003, época em que o Brasil lidava com o início de um novo governo e com as dúvidas do mercado financeiro sobre a política econômica que seria adotada daí para frente. Como cedo ficou claro o compromisso do novo governo com a estabilidade monetária e a responsabilidade fiscal, a aposta numa queda gradual e constante de juros fazia pleno sentido.

O resumo das estatísticas descritivas dos ativos utilizados está na tabela 1 .

Tabela 1

Estatísticas descritivas dos retornos nominais dos principais ativos (período: 2003:01 a 2007:12 - 60 observações)

\begin{tabular}{|c|c|c|c|c|c|c|c|c|c|}
\hline & \multirow[b]{2}{*}{ Poupança } & \multirow[b]{2}{*}{ Ibovespa } & \multicolumn{3}{|l|}{ Debênture } & \multicolumn{4}{|l|}{ FIDC } \\
\hline & & & $\begin{array}{c}\text { Nova } \\
\text { Marlim }\end{array}$ & $\begin{array}{c}\text { Debênture } \\
\text { Petrobras }\end{array}$ & $\begin{array}{l}\text { Debênture } \\
\text { Itaú }\end{array}$ & $\begin{array}{l}\text { Auto } \\
\text { Pan }\end{array}$ & $\begin{array}{l}\text { FIDC } \\
\text { Ideal }\end{array}$ & $\begin{array}{l}\text { FIDC } \\
\text { Máster }\end{array}$ & $\begin{array}{c}\text { DI } \\
\text { Futuro }\end{array}$ \\
\hline $\begin{array}{l}\text { Retorno médio } \\
\text { (\% ao mês) }\end{array}$ & $0,711 \%$ & $3,112 \%$ & $1,695 \%$ & $1,423 \%$ & $1,444 \%$ & $1,303 \%$ & $1,313 \%$ & $1,351 \%$ & $1,427 \%$ \\
\hline $\begin{array}{l}\text { Desvio padrão } \\
\text { (\% ao mês) }\end{array}$ & $0,114 \%$ & $6,036 \%$ & $0,670 \%$ & $0,668 \%$ & $0,311 \%$ & $0,288 \%$ & $0,242 \%$ & $0,246 \%$ & 0,535\% \\
\hline P-valor & {$[0,0000]$} & {$[0,0002]$} & {$[0,0000]$} & {$[0,0000]$} & {$[0,0000]$} & {$[0,0000]$} & {$[0,0000]$} & {$[0,0000]$} & {$[0,0000]$} \\
\hline
\end{tabular}

Os dados de poupança e da carteira de tesouraria do BNB foram obtidos no próprio Banco do Nordeste, na contabilidade da empresa e em área responsável pela pesquisa e tratamento de dados do mercado financeiro.

Os dados relacionados a debêntures foram extraídos do Sistema Nacional de Debêntures (<www.debentures.com.br >).

Os dados dos FIDCs foram obtidos no site sobre fundos de investimento Fortuna (<www.fortuna.com.br $>$ ). Por fim, os dados do Ibovespa e de contratos futuros de DI foram extraídos da agência internacional de notícias e informações econômico-financeiras Bloomberg, por meio de seu terminal empresarial. O comportamento das séries históricas dos dados utilizados pode ser visualizado nas figuras 1 e 2 . 
Figura 1

Retorno nominal Ibovespa

(período: 2003:01 a 2007:12 - 60 observações)

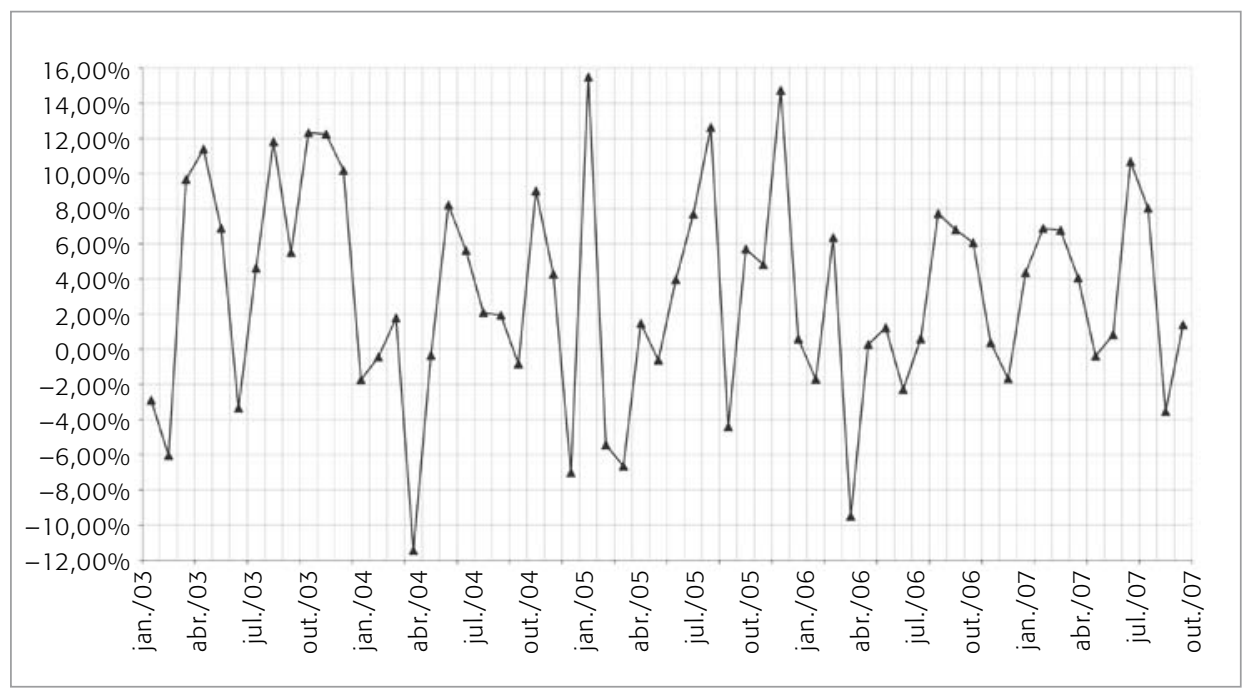

Figura 2

Retorno nominal dos principais ativos em questão

(período: 2003:01 a 2007:12 - 60 observações)

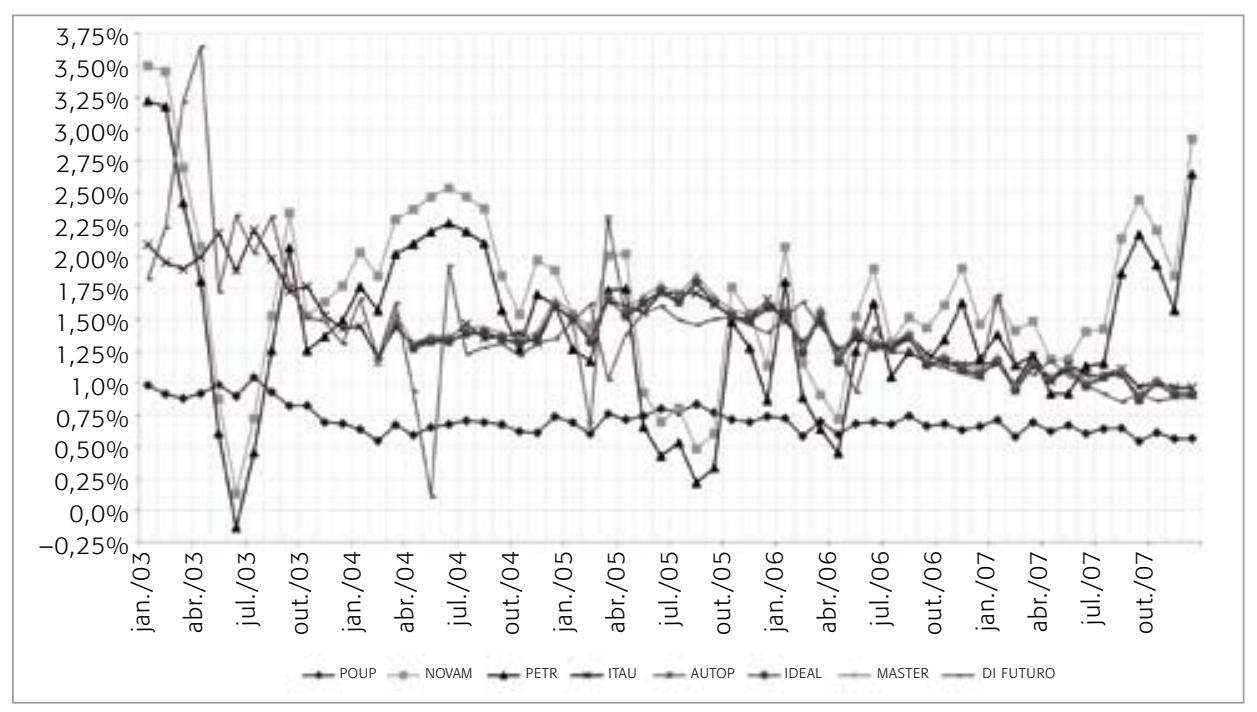




\section{Discussão dos resultados}

As tabelas 2 e 3 mostram os resultados obtidos com o modelo. A tabela 2 traz um resumo da carteira de tesouraria tradicionalmente empregada pelo banco, composta de ativos do mercado de renda fixa, operações compromissadas, CDI e ações. De acordo com os resultados, tem-se um relativamente baixo coeficiente de explicação, dado que o modelo procura explicar o comportamento de uma carteira majoritariamente representada por ativos de renda fixa tomando como base uma carteira de mercado composta de ativos de renda variável. Ambos os parâmetros, alfa de Jensen e beta de mercado, são estatisticamente significativos para um nível de $5 \%$, sendo o beta positivo de ordem de grandeza muito baixa, como seria de se esperar, considerando-se a política conservadora da instituição, sendo esta carteira um ativo de baixa volatilidade que segue o mercado de renda fixa, que em geral "influencia o mercado com uma correlação positiva". O alfa é positivo, sinalizando uma adequada estratégia por parte da tesouraria do banco, estando a instituição correndo menos risco do que o modelo estaria prevendo, ou mesmo tendo um maior ganho vis-à-vis o risco assumido.

Tabela 2

Resultados da carteira de tesouraria do BNB

\begin{tabular}{|lcccccc|}
\hline \multicolumn{7}{|c|}{$\mathrm{R}_{\text {Port i }}-\mathrm{R}_{\text {poup }}=\alpha_{\mathrm{i}}+\alpha_{\mathrm{i}}\left(\mathrm{R}_{\text {bov }}-\mathrm{R}_{\text {poup }}\right)+\mathrm{u}_{\mathrm{i}}$} \\
\hline Portfólio & \multicolumn{1}{|c|}{ Composição } & $\mathrm{R} 2$ & Alfa & P-valor & Beta & P-valor \\
BNB & $\begin{array}{l}\text { Renda fixa }+ \text { compromissadas } \\
+ \text { CDI }+ \text { ações }\end{array}$ & 0,170150 & 0,005304 & {$[0,0000]$} & 0,023243 & {$[0,0063]$} \\
\hline
\end{tabular}

Obs.: Estimação por meio do método de mínimos quadrados ordinários. Construção de matriz de variância e covariância com a utilização do estimador proposto por Newey e West.

A tabela 3 traz os resultados das carteiras alternativas sugeridas. Aqui, foram feitas combinações de forma a inserir outros ativos no portfólio da tesouraria do banco, especificamente debêntures das empresas: Nova Marlim, Petrobras e Itaú. Além dos FIDCs Auto Pan, Ideal e Máster. A distribuição dos ativos foi feita observando os limites de concentração por papel e por ativos privados. A tabela 4 traz os resultados das carteiras alternativas arrojadas, que não seguem mais os limites impostos à política de investimentos do BNB. 


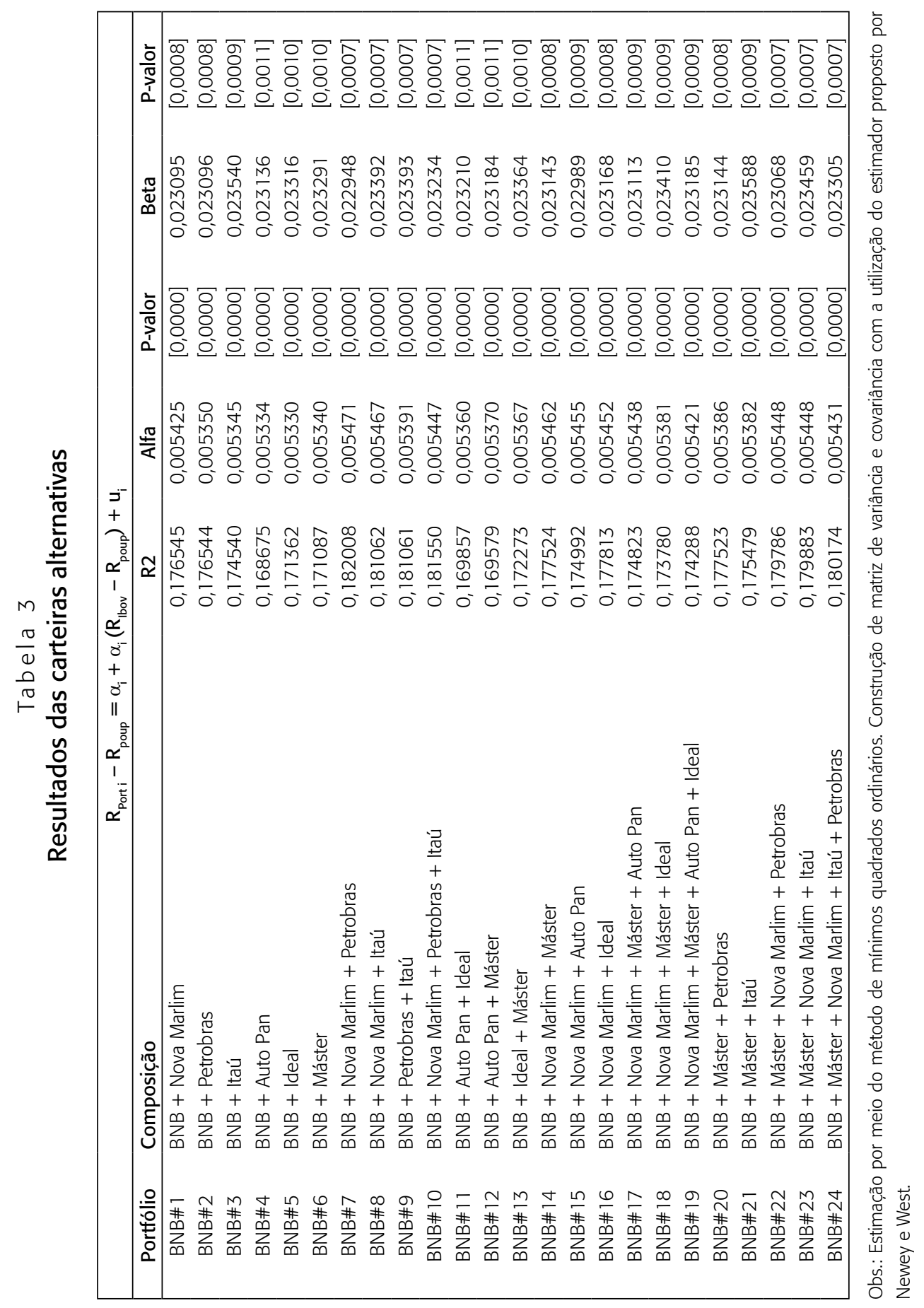




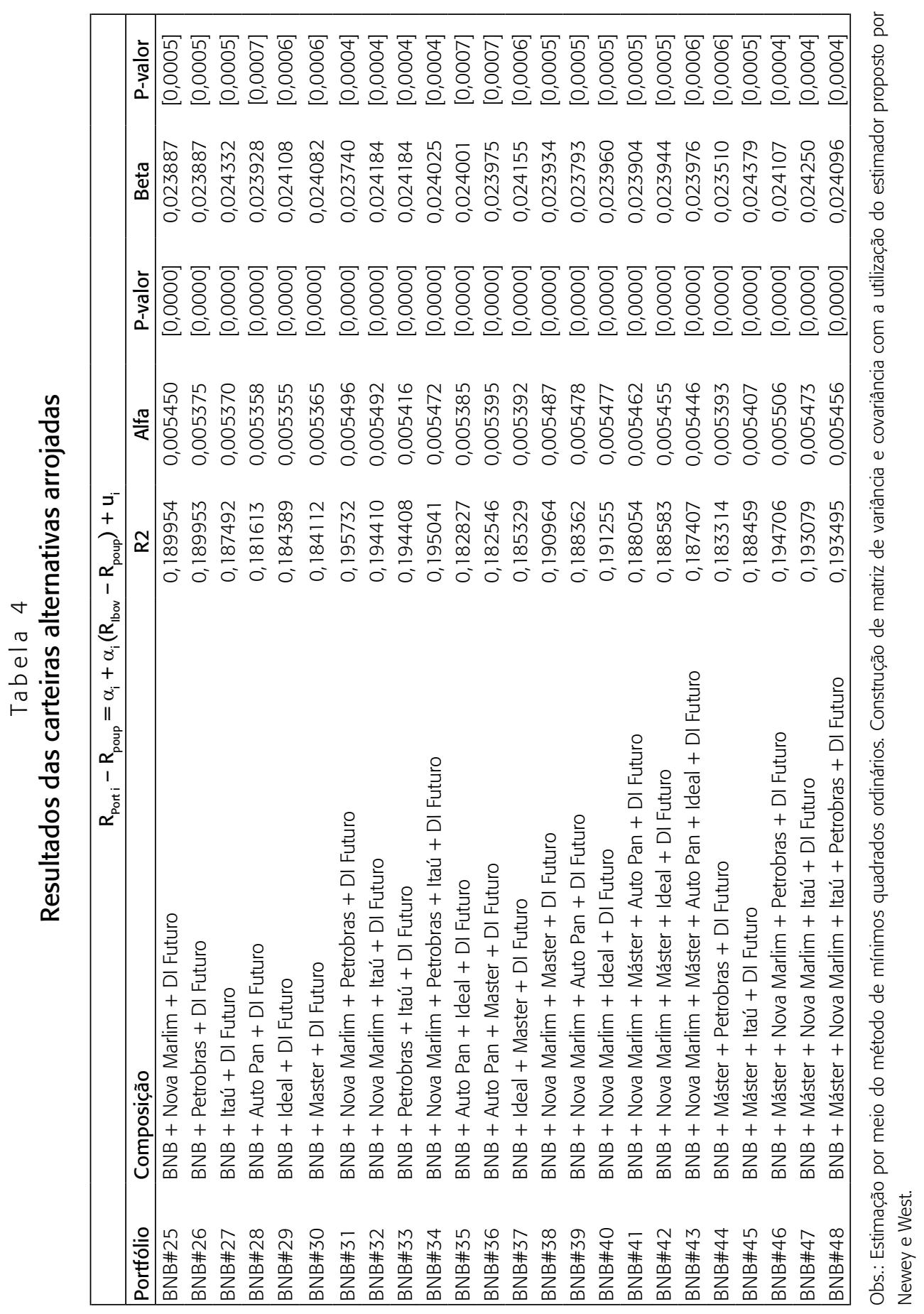


Em ambas as tabelas, é possível evidenciar um discreto aumento no coeficiente de explicação do modelo para a maioria dos portfólios propostos, um resultado intuitivo em razão da característica dos ativos componentes da carteira, deixando esta de ser meramente de renda fixa. Das 48 carteiras testadas, todas apresentaram ambos os parâmetros estatisticamente significativos a um nível de $5 \%$. Os coeficientes que mensuram a sensibilidade da carteira à carteira de mercado são de fato levemente superiores e possuem a mesma ordem de grandeza do beta da carteira do BNB. Ressalta-se que, para ambos os casos, as alterações efetuadas nas carteiras alternativas e nas carteiras alternativas arrojadas foram de pequena magnitude, em razão dos limites restritivos à política de investimentos da instituição, esperando-se que houvesse um aumento na capacidade de explicação do modelo acompanhado por aumentos discretos na magnitude dos betas das novas carteiras. Mesmo para o caso das carteiras que não obedecem à restrição, não seria muito informativo propor portfólios extremamente arriscados comuns a instituições financeiras privadas, que não deverão em nenhum momento ser aceitos quando de uma futura flexibilização dessas regras de investimento.

Observa-se que para todas as carteiras propostas os alfas de Jensen assumem valores ligeiramente superiores ao obtido para a carteira praticada pelo $\mathrm{BNB}$, um resultado não trivial, nem necessariamente esperado. Não se trata de obter retorno maior, em razão de serem as carteiras alternativas mais arriscadas. Trata-se do aumento de um risk adjusted return, ou do retorno ajustado pelo risco, evidenciando que todas as 48 carteiras alternativas estivessem ainda mais underpriced e, portanto, mais indicadas para compra que a praticada pelo BNB.

Mais especificamente, atendo-se à tabela 3 , ou seja, considerando-se o cumprimento dos limites estabelecidos pela política de tesouraria do BNB, o portfólio que obteve o melhor desempenho foi o \# 7, que combina os ativos tradicionalmente empregados pela tesouraria do banco mais uma parcela aplicada em debêntures das empresas Nova Marlim e Petrobras. Essa carteira apresentou um alfa de 0,005471, vis-à-vis 0,005304 obtido para a carteira do $\mathrm{BNB}$, o que corresponde: a um ganho mensal de $0,547 \%$ acima do que se esperaria que uma carteira dessa proporcionasse em termos de retorno com base no risco incorrido; e a um aumento percentual médio mensal de 0,0167\% em relação à carteira do banco. Em termos anuais, seria um ganho ajustado pelo risco de 0,2\%. Desprezível? Capaz de compensar a inserção legal de novos ativos que são atualmente estranhos à carteira padrão do banco?

Observe os resultados para o caso em que são sugeridas mudanças factíveis à atual política de gestão de tesouraria. Uma compensação maior pode 
ser obtida com carteiras mais arrojadas, como a \#31, que em acréscimo aos ativos do portfólio \#7 incorpora ainda contratos de DI futuro. Nesse caso, o ganho de retorno ajustado pelo risco seria de $0,23 \%$ ao ano. Mesmo não sendo um resultado esperado nem trivial, seria uma evidência capaz de gerar razoável ensejo para que ocorram eventuais mudanças de pequena magnitude na política de gestão de recursos de tesouraria do BNB ou ainda uma solicitação para que possa ser revista a Resolução no 2.099 , de 17 de agosto de 1994, do Banco Central?

Seria necessário um estudo mais aprofundado motivado por este artigo, em que se analisasse a questão de custo-benefício, uma vez que necessitaria de alocação de recursos para formação e capacitação de um corpo técnico mais completo, além de investimentos em novas bases de dados e softwares em finanças. Um indicativo parece sugerir a viabilidade dessa mudança institucional e principalmente da legislação. Somente em relação ao BNB, com sua carteira atual de $\mathrm{R} \$ 7,5$ bilhões estaria sendo essa mudança capaz de gerar um aumento ajustado pelo risco de $\mathrm{R} \$ 15$ milhões ao ano, certamente superior aos custos fixo e variável de ampliação da tesouraria do porte dessa instituição. Quando da mudança de legislação, esse aumento de receita (risk adjusted) poderia chegar ao patamar dos $\mathrm{R} \$ 17$ milhões.

\section{Graficamente}

A título de melhor visualização das carteiras testadas, apresentamos a fronteira eficiente construída com base na melhor carteira arrojada sugerida, a melhor carteira não arrojada e a carteira do banco (figura 3), e um gráfico com a linha de mercado de títulos (LMT, figura 4). Podemos perceber que a diferença entre as carteiras é mínima, sendo a do BNB a de maior desvio padrão e, ao mesmo tempo, a de menor retorno esperado entre as plotadas no gráfico.

Nota-se que, pelo gráfico da fronteira eficiente, o BNB teria melhores opções combinando o ativo livre de risco com ativos de mercado. No entanto, a empresa encontra restrições legais que proíbem sua participação acionária em empresas de capital aberto, servindo o gráfico, portanto, apenas para comparação das várias carteiras possíveis para o banco, dentro de suas limitações legais.

O gráfico da linha de mercado de títulos, por seu turno, mostra mais uma vez as carteiras agrupadas, denotando a diferença mínima entre elas e também a ínfima distância observada em relação à LMT. O Ibovespa não aparece na figura 4 para facilitar a visualização. 
Figura 3

Fronteira média-variância

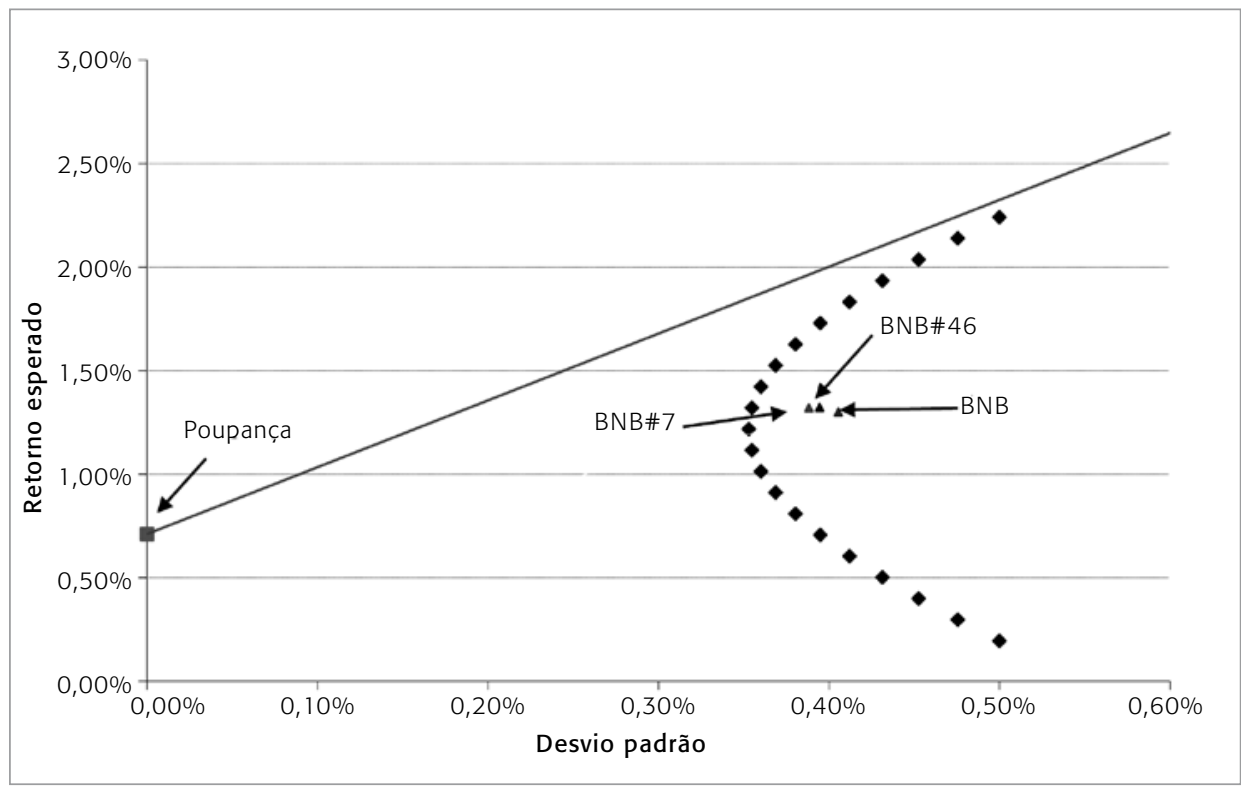

Figura 4

Linha de mercado de títulos

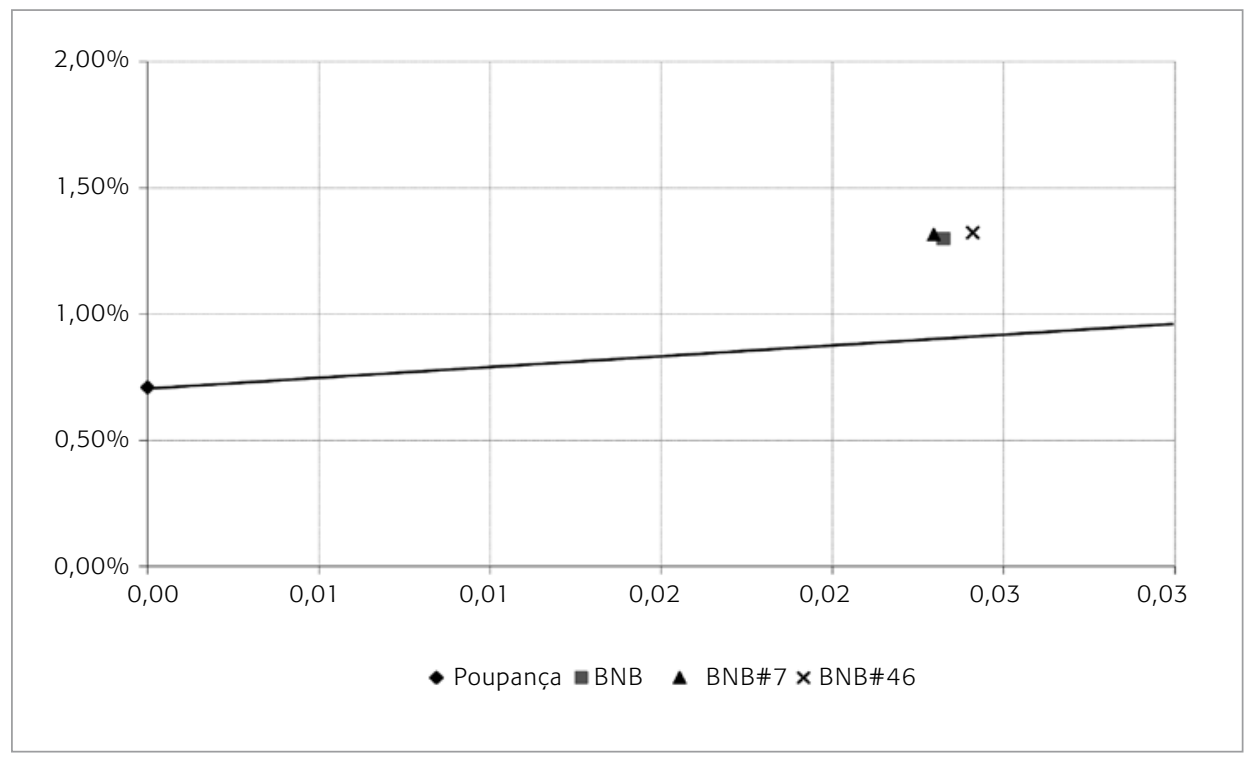




\section{Extensões e limitações}

\section{Taxa livre de risco}

Os resultados obtidos levaram em consideração a poupança como taxa livre de risco. Com relação a esse instrumento financeiro, sabe-se que o fundo garantidor de crédito (FGC), de responsabilidade do governo, garante atualmente apenas R \$ 60 mil de aplicações na poupança, de forma que acima desse valor, há o risco de crédito da instituição financeira responsável pela manutenção da conta. Haveria um error-in-variable problem? Ou seja, o uso de uma proxy não adequada? Segundo Matos e Simonassi (2008), em que se estima uma taxa hipotética livre de risco, o uso de instrumentos financeiros disponíveis como Selic, CDI, ou poupança como proxy para a inexistente taxa pode incorrer na alteração de resultados quando do uso de modelos de apreçamento de ativos, microfundamentados ou não. Ainda segundo esses autores, problema mais grave seria cometido com o uso da Selic como taxa livre de risco, uma vez que ela apresenta uma volatilidade inadequadamente alta e sendo o risco de default por parte do governo brasileiro existente, dada à tradição na sua utilização. Somente no século passado o governo brasileiro usou esse artifício cinco vezes. Ainda assim, foram testados os mesmos 48 portfólios quando da Selic como taxa livre de risco, com resultados qualitativamente robustos, no que se refere à hierarquia dos portfólios, à diferença percentual entre as carteiras alternativas e ao portfólio tradicional do banco, mesmo tendo havido mudança significativa da ordem de grandeza dos alfas, que passaram a ser negativos.

Uma extensão deste artigo, com a utilização de outra proxy que não a Selic, nem a poupança, pode utilizar a abordagem proposta por Matos e Simonassi (2008), o que gera uma taxa livre de risco com base em um fator estocástico de desconto para o Brasil, cuja volatilidade e o patamar são bem menores e mais aceitáveis que os observados para a taxa Selic e razoavelmente próximos para a poupança.

\section{Limitações do modelo}

Por fim, há de se reconhecer as limitações do modelo de Jensen, derivado do CAPM. Roll (1977) demonstrou que os testes empíricos ao CAPM dependem da proxy utilizada para a carteira de mercado, e, na versão original do modelo essa carteira era constituída por todos os ativos com risco e não apenas por ações. Apesar disso, nos testes habituais ao modelo CAPM, considera-se um 
índice de ações para proxy da carteira de mercado - no caso deste artigo, o índice Ibovespa. Roll defendeu que nunca se poderá testar empiricamente o CAPM, a menos que se considere a verdadeira carteira de mercado.

\section{Conclusão}

Em um contexto de trade-off incorrido por instituições financeiras públicas, que não possuem a tesouraria como prioridade, mas sim as atividades associadas ao desenvolvimento sustentável da região, seria razoável manter uma postura extremamente conservadora na gestão da carteira de investimentos, tendo-a como uma atividade complementar de segunda ordem? Nesse sentido, este artigo analisa o desempenho da carteira de investimentos do Banco do Nordeste do Brasil, a partir da medida de Jensen.

Mesmo não sendo possível fornecer uma definitiva análise de custo-benefício da mudança da política de gestão de recursos de tesouraria do BNB, ou ainda para a mudança de legislação, a ser feita em uma possível extensão deste artigo, incluindo mais instituições públicas de fomento, os ganhos quando de uma política menos conservadora de investimentos, em torno de 0,20\% a $0,23 \%$ ao ano, sugerem a viabilidade de tais mudanças institucionais.

\section{Referências}

BERNSTEIN, P. L. Against the gods: the remarkable story of risk. John Wiley \& Sons, Inc., 1996.

BONOMO, MARCO (Org.). Finanças aplicadas ao Brasil. Rio de Janeiro: FGV, 2002.

BODIE, Z.; MERTON, R. C. Finanças. Bookman, 2002.

JENSEN, M. C. The performance of mutual funds in the period 1945-1964. Journal of Finance, May 1968.

LEAL, R.; VILELLA, P. A. A análise de estilo e a sua aplicação na análise de desempenho de fundos balanceados. In: Gestão de investimentos e fundos. Financial Consultoria, 2006.

LINTNER, J. Security prices, risk and maximal gains from diversification. Journal of Finance, Dec. 1965. 
MARKOWITZ, H. Portfolio selection. Journal of Finance, Mar. 1952.

MATOS, P.; SIMONASSI, A. On the empirics of the risk-free rate: the Brazilian case. Working paper. 2008.

MERTON, R. C. An intertemporal capital asset pricing model. Econometrica, set. 1973.

NEWEY, W.; WEST, K. A simple, positive semi-definite, heteroscedasticity and autocorrelation consistent covariance matrix. Econometrica, 1987.

OWEN, J.; RABINOVITCH, R. Ranking portfolio performance by a joint means and variances equality test. Journal of Applied Economics, May 1998.

ROLL, R. A critique of the asset pricing theory's tests. Journal of Financial Economics, 1977.

SHARPE, W. F. Capital asset prices: a theory of market equilibrium under conditions of risk. The Journal of Finance, Sept. 1964.

SOUSA, A. F.; LUPORINI, C. E. M. Análise empírica do desempenho dos fundos mútuos de ações brasileiros. Cadernos de Pesquisa em Administração, jun. 1997.

Vargas, G. Performance de fundos de ações no Brasil. In: Gestão de investimentos e fundos. Financial Consultoria, 2006a.

. Indicadores de investimentos e de seleção de fundos. In: Gestão de investimentos e fundos. Financial Consultoria, 2006b. .; Leal, R. Gestão de investimento e fundos. Atlas, 2006. 